\title{
EFEKTIVITAS KEMAMPUAN MENGGAMBAR SKETSA \\ ORGAN PENCERNAAN RUMINANSIA DAN MANUSIA \\ UNTUK MENINGKATKAN PENGUASAAN KONSEP MAHASISWA
}

\author{
Lilis Suhaerah, \\ Fitri Aryanti \\ Universitas Pasundan \\ Bandung, Indonesia \\ E-mail: lilissuhaerah@unpas.ac.id
}

\begin{abstract}
Abstrak
Media pembelajaran merupakan suatu hal yang penting karena dapat memberikan variasi dalam proses belajar mengajar. Media pembelajaran yang digunakan pada penelitian ini berupa powerpoint, torso organ pencernaan dan gambar sketsa mahasiswa. Tujuan penelitian ini adalah untuk mengetahui efektivitas kemampuan menggambar sketsa organ pencernaan pada mata kuliah struktur hewan dalam meningkatkan penguasaan konsep mahasiswa. Metode yang digunakan yaitu metode eksperimen semu (quasi eksperimen) dengan the static-group pretest-posttest design. Hasil penelitian yang diperoleh menunjukkan adanya peningkatan skor pada masing-masing kelas, skor posttest di kelas eksperimen 1 yaitu 94.40 dan di kelas eksperimen 2 yaitu 85.40 dari skor maksimum 100. Perbandingan rerata skor $N$ gain 0,34 pada kelas eksperimen 1 dan 0,30 pada kelas eksperimen 2 yang masing-masing termasuk ke dalam kategori sedang. Berdasarkan hasil penelitian dan analisis data dapat disimpulkan terdapat peningkatan penguasaan konsep mahasiswa melalui kemampuan menggambar sketsa organ pencernaan pada mata kuliah struktur hewan.
\end{abstract}

Kata Kunci: menggambar sketsa, organ pencernaan, struktur hewan, penguasaan konsep.

\begin{abstract}
Learning media is an important thing because it can provide variation in teaching and learning process. Learning media used in this research are powerpoint, torso digestive organs and student draw sketches. The purpose of this research is to know the skills of draw sketches of the digestive organs in animal structure course to increase the mastery of student concept. The method used the quasi eksperiment with the staticgroup pretest-posttest design. The result showed that there was an increase of score in each class, the posttest score in the first experiment class was 94.40 and the second experimental class was 85.40 from the maximum score 100 . The average comparison of the $\mathrm{N}$-gain score of 0.34 in the experimental classes 1 and 0,30 in the experimental class 2, each of which belongs to the moderate category. Based on the results of research and data analysis can be concluded that was improvement mastery of student concept through draw sketches of the digestive organs in animal structure course.
\end{abstract}

Keywords: draw sketches, digestive organs, animal structures, mastery of concepts.

\section{PENDAHULUAN}

Pembelajaran dengan menggunakan media bukan suatu hal yang baru dalam dunia pendidikan. Media pembelajaran merupakan suatu alat yang berfungsi sebagai perantara atau penyampai isi berupa informasi pengetahuan secara visual dan verbal untuk keperluan pendidikan dan pengajaran. Angkowo and Kosasih (2007) mengungkapkan bahwa media merupakan salah satu faktor yang turut menentukan keberhasilan pengajaran karena sangat membantu dalam menyampaikan materi pembelajaran.

Kegiatan belajar merupakan kegiatan interaksi yang termediasi dalam lingkungan sosial dengan perkembangan kemampuan setiap orang yang meliputi aspek kognitif, afektif dan psikomotor. Miarso (2008) mengungkapkan bahwa belajar pada hakekatnya merupakan bagian terpenting dari proses sosial.
Kegiatan belajar merupakan interaksi antara pembelajar (learner) dengan sesama warga belajar, interaksi dengan guru/dosen/instruktur, interaksi dengan kelompok, interaksi dengan isi ajaran, dan interaksi dengan berbagai sumber belajar lain.

Jenis-jenis media pembelajaran sangat beragam yaitu media audio visual bergerak, media audio visual diam, media display, media audio, media grafis dan TIK (microsoft word, microsoft powerpoint). Powerpoint merupakan salah satu media yang sering digunakan di dalam kelas. Powerpoint dapat menjadikan penyajian materi pembelajaran lebih menarik, memberikan informasi secara visual kepada mahasiswa dan dapat disimpan dalam bentuk data optik atau magnetik sehingga mudah untuk dibawa kemanapun dan dapat diperbanyak sesuai kebutuhan. Faelasofi (2015) dalam penelitiannya menyatakan 
bahwa hasil belajar mahasiswa di kelas menjadi lebih baik dengan pembelajaran yang menggunakan media pembelajaran microsoft office powerpoint dibandingkan dengan tanpa menggunakan media pembelajaran microsoft office powerpoint.

Selain itu juga penelitian dengan menggunakan Problem-Based Learning (PBL) yang terintegrasi dengan metode pembelajaran ICT (Information and Communication Technology) menunjukkan nilai tes prestasi yang tinggi. ICT yang digunakan pada penelitian ini berupa Microsoft Word dan Microsoft PowerPoint (Osman \& Kaur, 2014).

Penggunaan powerpoint dalam pembelajaran merupakan bukan hal yang baru, pembuatan bahan presentasi dapat dilakukan dengan mudah dan cepat. Keadaan tersebut memang sangat mendukung kelancaran proses kerja dalam membuat bahan presentasi berbagai mata kuliah bagi tenaga pendidik ataupun peserta didik Permasalahan kadang terjadi pada saat menyusun materi, bahan ajar bisa dengan mudah dicopy sebagian atau secara keseluruhan tanpa memperhatikan dan memahami esensi dari materi tersebut, apalagi jika pembelajaran hanya dilakukan secara satu arah (teacher center) sehingga kegiatan bermakna dalam pembelajaran menjadi terabaikan karena mahasiswa tidak dilibatkan langsung dalam pembelajaran. Penggunaan powerpoint dapat membantu mahasiswa dengan arahan dan penjelasan dari dosen agar tidak terjadi pembelajaran yang hanya satu arah saja, selain itu mahasiswa dapat mendiskusikan hal-hal yang tidak dimengerti yang terdapat dalam slide powerpoint (Tanner, 2012). Sedangkan menurut Safita (2012) dalam penelitiannya menyatakan bahwa pada pembelajaran Biologi, mahasiswa dituntut untuk terampil dalam membuat dan mengembangkan media pembelajaran dengan melakukan praktik atau pelatihan secara langsung. Agar tercapainya proses pembelajaran tersebut, selain menggunakan powerpoint, dilakukan juga kegiatan menggambar secara langsung organ pencernaan ruminansia dan manusia sehingga hal tersebut akan meningkatkan aktivitas mahasiswa dan pembelajaran menjadi lebih bermakna serta diharapkan dapat meningkatkan pemahaman konsep mahasiswa.

\section{METODE}

Metode penelitian yang digunakan yaitu quasi experiment dengan desain penelitian the static-group pretest-posttest design (Fraenkel, Wallen, \& Hyun, 1993). Metode ini digunakan untuk mendapatkan informasi dan efektifitas kemampuan menggambar sketsa organ-organ pencernaan ruminansia dan manusia dalam meningkatkan penguasaan konsep mahasiswa pada mata kuliah struktur hewan.

Populasi dalam penelitian ini sebanyak 90 mahasiswa. Sampel penelitian terdiri dari dua kelas yaitu kelas A sebanyak 35 mahasiswa sebagai kelas eksperimen-1 dan kelas B sebanyak 35 mahasiswa sebagai kelas eksperimen-2.
Penelitian dilakukan 2 kali pertemuan pada masing-masing kelas, pengumpulan data dilakukan dengan memberikan instrument pada mahasiswa berupa soal essay dan soal menggambar organ pencernaan ruminansia dan manusia. Data kuantitatif pada penelitian ini berupa skor tes awal dan tes akhir penguasaan konsep. Perhitungan Gain ternormalisasi dilakukan berdasarkan data tersebut yang bertujuan untuk mengetahui kategori peningkatan penguasaan konsep sebelum dan sesudah pembelajaran

\section{HASIL DAN PEMBAHASAN}

Hasil perhitungan skor pretest, posttest, N-Gain dan uji statistik pada kelas eksperimen 1 dan eksperimen 2 dapat dilihat pada Tabel 1 dan Tabel 2.

Tabel 1. Rekapitulasi Pretest Posttest Penguasaan Konsep Kelas Eksperimen 1

\begin{tabular}{lccc}
\hline & \multicolumn{3}{c}{ KELAS EKSPERIMEN 1 } \\
& Pretest & Posttest & N-Gain \\
\hline Jumlah & 69.30 & 94.40 & 11.96 \\
Skor Maksimum & 3.00 & 3.40 & 0.60 \\
Skor Minimum & 1.30 & 1.40 & 0.00 \\
Skor Rata-Rata & 1.98 & 2.70 & 0.34 \\
\% Skor Rata-Rata & 49.50 & 67.43 & 8.55 \\
Simpangan Baku & 0.42 & 0.35 & 0.16 \\
\hline \multicolumn{4}{c}{ Berdistribusi Normal } \\
\hline Sig. $\boldsymbol{\alpha}=\mathbf{0 . 0 5}$ & Uji Normalitas \\
Keterangan & 0.13 & 0.07 \\
\hline
\end{tabular}

Tabel 2. Rekapitulasi Pretest Posttest Penguasaan Konsep Kelas Eksperimen 2

\begin{tabular}{lccc}
\hline & \multicolumn{3}{c}{ KELAS EKSPERIMEN 2 } \\
& Pretest & Posttest & N-Gain \\
\hline Jumlah & 62.20 & 85.40 & 10.36 \\
Skor Maksimum & 2.80 & 3.30 & 0.58 \\
Skor Minimum & 0.70 & 1.10 & 0.05 \\
Skor Rata-Rata & 1.78 & 2.44 & 0.30 \\
\% Skor Rata-Rata & 44.43 & 61.00 & 7.40 \\
Simpangan Baku & 0.49 & 0.48 & 0.15 \\
\hline \multicolumn{3}{c}{ Berdistribusi Normal } \\
\hline Sig. $\boldsymbol{\alpha}=\mathbf{0 . 0 5}$ & Uji Normalitas \\
\hline Keterangan & 0.20 & 0.07 \\
\hline
\end{tabular}

Tabel 3. Rekapitulasi Uji Statistik Penguasaan Konsep Kelas Eksperimen 1 dan Kelas Eksperimen 2

\begin{tabular}{lccc}
\hline \multicolumn{4}{c}{ Uji Homogenitas } \\
\hline Sig. $\boldsymbol{\alpha}=\mathbf{0 . 0 5}$ & 0.58 & 0.24 & 0.78 \\
Keterangan & Homogen & Homogen & Homogen \\
\hline \multicolumn{4}{c}{ Uji T-test } \\
\hline
\end{tabular}




\begin{tabular}{lccc}
\hline Sig. $\boldsymbol{\alpha}=\mathbf{0 . 0 5}$ & 0.07 & 0.01 & 0.22 \\
Keterangan & Homogen & Homogen & Homogen
\end{tabular}

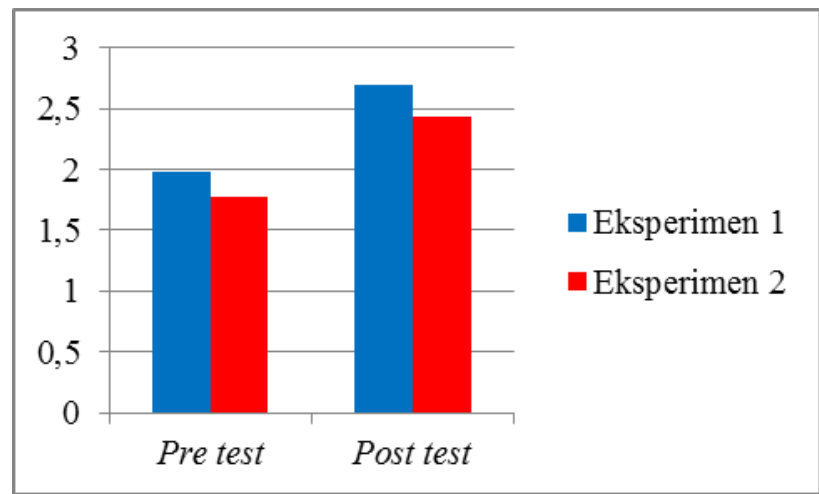

Gambar 1. Perbandingan Rerata Skor Pretest dan Posttest Penguasaan Konsep

Gambar 1. menunjukkan adanya peningkatan skor pretest dan posttest di kelas eksperimen 1 dan kelas eksperimen 2. Skor posttest di kelas eksperimen 1 yaitu 94.40 dan di kelas eksperimen 2 yaitu 85.40 dari skor maksimum 100.

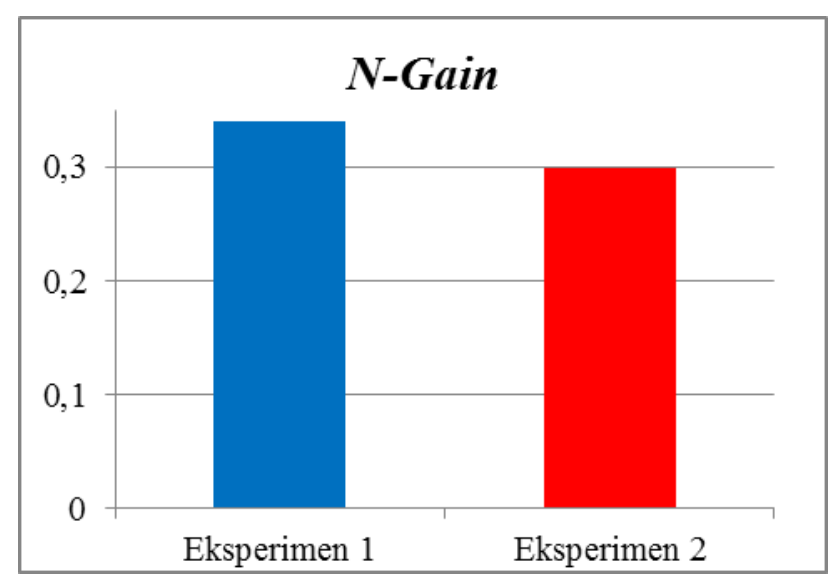

Gambar 2. Perbandingan Rerata N-Gain Penguasaan Konsep

Gambar 2. menunjukkan $N$-Gain penguasaan konsep di kelas eksperimen 1 lebih tinggi daripada di kelas eksperimen 2. Peningkatan penguasaan konsep di kelas eksperimen 1 yaitu 0,34 dan di kelas eksperimen 2 yaitu 0,30 yang masing-masing termasuk ke dalam kategori sedang.

Berdasarkan hasil pretest dan posttest, diketahui bahwa terdapat peningkatan penguasaan konsep mahasiswa pada kelas eksperimen 1 dan eksperimen 2, tetapi peningkatan tersebut belum mencapai skor yang maksimal. Pembelajaran dengan menggunakan media pada umumnya dapat membantu meningkatkan motivasi belajar mahasiswa. Apriana (2015) menyatakan bahwa penggunaan media pembelajaran pada beberapa mata kuliah dapat meningkatkan keterampilan mahasiswa dalam menggunakan berbagai media pembelajaran dengan nilai yang diperoleh berkisar dari cukup, baik dan sangat baik
Jenis-jenis media gambar dalam pembelajaran dapat disajikan dalam bentuk poster, kartun, komik, gambar fotografi, slide, bagan diagram. Menurut Tegeh (Kustandi, 2016) media gambar dilihat dari pandangan media grafis merupakan gambar-gambar hasil lukisan tangan, hasil cetakan dan hasil karya seni fotografi. Penyajian obyek dalam bentuk gambar dapat disajikan melalui bentuk nyata maupun kreasi khayalan sesuai dengan bentuk yang pernah dilihat oleh orang yang menggambarnya. Media grafis merupakan hal yang sederhana, tidak bergerak, mudah digunakan dan mudah disimpan.

Pembelajaran pada penelitian ini dilakukan dengan menggunakan media pembelajaran berupa powerpoint dan juga menggambar sketsa berupa gambar organ pencernaan pada ruminansia dan manusia. Powerpoint merupakan media yang sering digunakan dalam pembelajaran. Keunggulan powerpoint menurut Sanaky (2011) diantaranya yaitu :

1) Praktis, dapat digunakan untuk semua ukuran kelas.

2) Memberikan kemungkinan tatap muka dan mengamati respon dari penerima pesan.

3) Memberikan kemungkinan pada penerima pesan untuk mencatat

4) Memiliki variasi teknik penyajian dengan berbagai kombinasi warna atau animasi.

5) Dapat digunakan berulang-ulang.

6) Dapat dihentikan pada setiap sekuens belajar karena kontrol sepenuhnya pada komunikator.

Sedangkan kelemahan penggunaan powerpoint dalam pembelajaran diantaranya yaitu :

1) Pengadaan alat mahal dan tidak semua sekolah memiliki.

2) Memerlukan perangkat keras (komputer) dan LCD untuk memproyeksikan pesan.

3) Memerlukan persiapan yang matang.

4) Diperlukan keterampilan khusus dan kerja yang sistematis untuk menggunakannya.

5) Menuntut keterampilan khusus untuk menuangkan pesan atau ide yang baik pada desain program komputer powerpoint sehingga mudah dicerna oleh penerima pesan.

Beberapa kelemahan yang disebutkan diatas sebagian besar sudah dapat teratasi, hanya saja mahasiswa perlu lebih di aktifkan dan memusatkan perhatiannya terhadap segala bentuk aspek pembelajaran dengan cara menggambar langsung bentuk 2D organ-organ pencernaan ruminansia dan manusia. Menurut Nugroho (2013) pada saat pembelajaran berlangsung terdapat beberapa kendala diantaranya yaitu keadaan pasif di dalam kelas sehingga perlu motivasi dan inovasi dalam melaksanakan proses pembelajaran.

Keadaan tersebut sangat dipengaruhi oleh peranan seorang pendidik dalam mengelola pembelajaran untuk menumbuh kembangkan potensi pada setiap diri mahasiswa dalam memahami berbagai konsep. 
Winkel (2003) mengemukakan bahwa penguasaan konsep dapat diperoleh melalui bantuan benda-benda, gambar dan penjelasan verbal serta menuntut kemampuan untuk menemukan ciri-ciri yang sama pada sejumlah obyek. Menggambar 2D organ-organ secara langsung bertujuan agar mahasiswa tidak pasif hanya dengan memperhatikan setiap slide power point. Aktivitas menggambar sketsa bentuk 2D dapat menggali potensi yang menyangkut aspek kognitif, afektif dan psikomotorik serta dapat merangsang kreativitas mahasiswa untuk belajar.

Proses pembelajaran di kelas tidak dapat hanya dilakukan dengan metode ceramah saja, tetapi juga dilakukan dengan berbagai inovasi dan juga bantuan multimedia untuk meningkatkan motivasi belajar siswa dan juga mencapai tujuan pembelajaran. Alanda (2012) mengemukakan mengenai peranan media digambarkan Edgar Dale dalam sebuah kerucut yang dinamakan Edgar Dale cone of experience atau Kerucut Pengalaman Edgar yaitu siswa hanya dapat mengingat $10 \%$ dari materi yang dibaca, $20 \%$ materi dari yang mereka dengar, 30\% materi jika mereka melihat, $50 \%$ materi dapat diingat jika mereka melihat dan mendengarkan, $70 \%$ dapat mereka ingat bila mereka menyatakan dan menulis materi, dan $90 \%$ dapat mereka kuasai jika mereka mempraktekkannya secara langsung.

Kegiatan menggambar sketsa organ pencernaan ruminansia dan manusia secara langsung diharapkan dapat meningkatkan penguasaan konsep mahasiswa dan dapat meningkatkan aktivitas pembelajaran menjadi lebih bermakna. Rahmah (2013) mengungkapkan ada tiga kebaikan belajar bermakna, yaitu :

1) Informasi yang dipelajari secara bermakna lebih lama diingat

2) Informasi baru yang telah dikaitkan dengan konsep-konsep relevan sebelumnya dapat meningkatkan konsep yang telah dikuasai sebelumnya sehingga memudahkan proses belajar mengajar berikutnya untuk memberi pelajaran yang mirip

3) Informasi yang pernah dilupakan setelah pernah dikuasai sebelumnya masih meninggalkan bekas sehingga memudahkan proses belajar mengajar untuk materi pelajaran yang mirip walaupun telah lupa.

Kelebihan dari penelitian ini yaitu mahasiswa dapat meningkatkan kemampuan menggambar sketsa 2D dan diharapkan dapat meningkatkan pemahaman konsep mahasiswa serta mampu merepresentasikan gambar organ-organ pencernaan ruminansia dan manusia seperti yang dikemukakan oleh Suprapto (2012) dalam penelitiannya bahwa kemampuan berpikir spasial mahasiswa dapat ditingkatkan dalam membangun gambar 2D, 3D dan model bangun 3D.

Adapun kekurangan pada penelitian ini yaitu memerlukan waktu yang lebih lama untuk membentuk sketsa organ-organ pencernaan ruminansia dan manusia secara detail, oleh karena itu perlu diperhatikan alokasi waktu pelaksanaan pembelajaran

\section{PENUTUP}

\section{Simpulan}

Berdasarkan hasil analisis data dalam penelitian ini maka dapat ditarik kesimpulan bahwa kemampuan menggambar sketsa organ pencernaan ruminansia dan manusia pada mata kuliah struktur hewan dapat membantu meningkatkan penguasaan konsep mahasiswa. Hal tersebut dapat dilihat dari $N$ gain soal essay dan gambar struktur organ pencernaan ruminansia dan manusia. $\mathrm{N}$-Gain soal essay penguasaan konsep di kelas eksperimen 1 lebih tinggi daripada di kelas eksperimen 2. Peningkatan penguasaan konsep di kelas eksperimen 1 yaitu 0,34 dan di kelas eksperimen 2 yaitu 0,30 yang masingmasing termasuk ke dalam kategori sedang. Hasil penelitian ini akan dijadikan sebagai bahan evaluasi dengan memperbaiki kekurangan dalam pembelajaran untuk meningkatkan kualitas pendidikan.

\section{Saran}

Berdasarkan temuan hasil penelitian memberikan gambaran bahwa kreatifitas dan inovasi sangat penting dalam pembelajaran. Penggunaan media pembelajaran sangat membantu dalam proses belajar mengajar, tetapi pada pelaksanaannya seorang dosen harus memperhatikan beberapa aspek baik aspek kognitif, afektif dan psikomotor. Seperti halnya pada saat penggunaan media slide power point, mahasiswa harus dilibatkan dalam kegiatan pembelajaran dan tidak hanya memperhatikan melalui slide powerpoint saja. Kegiatan menggambar sketsa bentuk 2D organ pencernaan ruminansia dan manusia dapat meningkatkan aktivitas mahasiswa sehingga ikut terlibat di dalamnya. Aktivitas tersebut akan mengakibatkan perubahan dalam dirinya, baik berupa perubahan pengetahuan maupun kemahiran mahasiswa.

\section{DAFTAR PUSTAKA}

Angkowo, R., \& Kosasih, A. (2007). Optimalisasi media pembelajaran: Gramedia Widiasarana.

Apriana, E. (2015). Penggunaan Berbagai Media Pembelajaran Biologi Pada Mata Kuliah Pembelajaran Mikro (Microteaching). Jurnal Biology Education, 4(1).

Faelasofi, R. (2015). Penggunaan Media Pembelajaran Microsoft Office Powerpoint Pada Pokok Bahasan Peluang. JURNAL e-DuMath, 1(1).

Fraenkel, J. R., Wallen, N. E., \& Hyun, H. H. (1993). How to design and evaluate research in education (Vol. 7): McGraw-Hill New York.

Miarso, Y. (2008). Pengembangan Terkini Sistem Pendidikan dan Pembelajaran di Perguruan Tinggi. Unpublished Paper. 
Nugroho, A. S. (2013). Peningkatkan Penguasaan Konsep Dengan Model Pembelajaran Konsep Dalam Pembelajaran IPS di Sekolah Dasar. Jurnal Penelitian Pendidikan Guru Sekolah Dasar, 1(2).

Osman, K., \& Kaur, S. J. (2014). Evaluating Biology Achievement Scores in an ICT integrated PBL Environment. Eurasia Journal of Mathematics, Science \& Technology Education, 10(3).

Rahmah, N. (2013). Belajar Bermakna Ausubel. AlKhwarizmi: Jurnal Pendidikan Matematika dan Ilmu Pengetahuan Alam, 1(1), 43-48.

Safita, R. (2012). Pelatihan Keterampilan Mengembangan Media Pembelajaran Biologi oleh Mahasiswa Tadris Biologi Fakultas Tarbiyah IAIN STS Jambi (Studi Kasus Mata Kuliah Media Pembelajaran Biologi). EDU_BIO| Jurnal Pendidikan Biologi, 3.

Sanaky, H. A. (2011). Media Pembelajaran Buku Pegangan Wajib Guru dan Dosen. Yogyakarta: Kaukaba Dipantara.

Suprapto, P. K. (2012). Pengembangan Program Perkuliahan Anatomi Tumbuhan Berbasis Visuospasial Melalui Representasi Mikroskopis Sistem Jaringan Tumbuhan untuk Meningkatkan Penalaran dan Penguasaan Konsep Calon Guru Biologi. Bandung Indonesia: Disertation, Universitas Pendidikan Indonesia.

Tanner, K. D. (2012). Promoting student metacognition. CBE-Life Sciences Education, 11(2), 113-120.

Winkel, W. S. (2003). Psikologi pengajaran. Jakarta: PT. Gramesi. 